\title{
GRANULAÇÃO DE AMIDO DE MILHO POR ATOMIZAÇÃO DE ALGINATO DE SÓDIO EM CLORETO DE CÁLCIO
}

\author{
G. FELTRE, G. C. DACANAL
}

\author{
Universidade de São Paulo, Faculdade de Zootecnia e Engenharia de Alimentos, Departamento de \\ Engenharia de Alimentos \\ E-mail para contato: gabriela.feltre@usp.br
}

\begin{abstract}
RESUMO - O objetivo deste trabalho foi o estudo do método de produção de partículas aglomeradas de amido de milho por meio da atomização de solução de alginato de sódio e amido nativo em cloreto de cálcio. As partículas aglomeradas foram filtradas e então submetidas à secagem convectiva em estufa, a $65^{\circ} \mathrm{C}$, e liofilização. Os grânulos desidratados foram analisados por microscopia eletrônica de varredura. Pôde-se observar que os grânulos apresentaram pontes sólidas, constituídas por alginato de cálcio, porém, não houve aderência completa do alginato de cálcio na superfície do amido de milho, ou seja, o recobrimento dos grânulos de amido foi apenas parcial. As análises de potencial zeta indicaram que o amido de milho e o alginato de sódio possuem valores negativos, o que justifica a falta de aderência do ligante sobre a superfície do amido, ocasionando o revestimento incompleto.
\end{abstract}

\section{INTRODUÇÃO}

O amido é o carboidrato mais comum produzido pelas plantas, está em forma de grânulos que existem naturalmente dentro das células e é a maior fonte de carboidratos na alimentação humana (SINGH et. al., 2010; SINGH et al., 2003). Ele é o carboidrato de reserva de muitas plantas e é depositado como grânulo insolúvel e semicristalino em tecidos de reserva como grãos, tubérculos e raízes e seu tamanho e forma dependem da espécie e da maturidade da planta (MANNERS, 1988; COPELAND et al., 2009). A quantidade de umidade do grânulo de amido nativo está em torno de 10\%. A amilose e a amilopectina correspondem a 98\%-99\% da massa em base seca dos grânulos nativos; o restante são pequenas quantidades de lipídios, minerais e fósforo na forma de fosfatos esterificados para hidrólise de glicose (COPELAND et al., 2009). Os grânulos de amido têm em média de 1 a $100 \mu \mathrm{m}$ de diâmetro (COPELAND et al., 2009). Os grânulos podem ocorrer individualmente ou como componente de um grânulo maior. No trigo, centeio e cevada, os grânulos possuem distribuição de tamanho de partículas bimodal. A diversidade na forma dos grânulos de amido e a constituição de suas moléculas influenciam em sua funcionalidade (COPELAND et al., 2009), como por exemplo, sua utilização em processos alimentícios como estabilizante, geleificante, encapsulante e para melhoramento da textura dos alimentos (SINGH et al., 2007).

O amido é semicristalino in natura com variações nos níveis de cristalinidade (SINGH et al., 2003). A região cristalina é composta por polímeros de amilopectina que se ligam para formar cristais durante a gelatinização (TESTER et al., 2004); já a região amorfa é composta por pontos de ramificação de amilose e amilopectina (DONALD, 2001). A maior porção presente no amido é de 


\section{9 a 22 de outubro de 2014 \\ Florianópolis/SC}

amilopectina, que corresponde a cerca de $70 \%$ a $80 \%$ do grânulo (MANNERS, 1988).

A amilose apresenta cadeia linear longa, com unidades de D-glicose e em torno de $99 \%$ das ligações do tipo $\alpha-(1 \rightarrow 4)$ (SINGH et al., 2010; TESTER et al., 2004; SINGH et al., 2003). A amilose tem um peso molecular entre 105 u e 106 u e grau de polimerização (DP) de 1000 a 10000 unidades de glicose. Menos que $0,5 \%$ da glicose na amilose são de ligações $\alpha-(1 \rightarrow 6)$, e sua estrutura possui de 3 a 11 cadeias (COPELAND et al., 2009). A amilopectina é um polímero maior que a amilose, com peso molecular aproximado de 107 u a 109 u (MUA; JACKSON, 1997). A amilopectina tem aproximadamente $5 \%$ de sua glicose em ligações $\alpha-(1 \rightarrow 6)$, e em torno de $95 \%$ de ligações $\alpha-(1 \rightarrow 4)$ (TESTER et al., 2004).

A aglomeração de partículas, também conhecida como granulação ou desenho de partículas (IVESON et al., 2001), é um processo muito utilizado na indústria de alimentos, pois permite melhorar ou modificar as propriedades de sólidos particulados para seu manuseamento. Fluidez, resistência mecânica e capacidade de umedecimento são algumas das propriedades que se deseja modificar num produto submetido à aglomeração (TURCHIULI et al., 2005). A aglomeração consiste na modificação de tamanho de partículas, decorrente da união das mesmas na presença um líquido ligante geralmente atomizado em leitos fluidizados, de jorro, e tambores rotativos, cada um operando com diferentes parâmetros, para então a formação de uma estrutura maior chamada de agregado poroso, que se trata de uma partícula maior (DACANAL; MENEGALLI, 2009).

O mecanismo de aglomeração das partículas ocorre com a atomização de um líquido, que pode ser água ou uma solução ligante, dependendo da natureza do material a ser aglomerado, a uma pressão relativa. O líquido é pulverizado em pequenas gotículas através de um bico aspersor que entram em contato com a superfície das partículas finas que se encontram em fluxo, umedecendo-as e tornando-as mais pegajosas (DACANAL, 2009). Existem três passos para o crescimento progressivo dos grânulos finos. O primeiro deles é o umedecimento e nucleação, em que as partículas menores se unem; o segundo é a coalescência, em que os aglomerados maiores se combinam e o terceiro em que há desgaste e quebra, ou seja, os aglomerados maiores se quebram em decorrência do atrito gerado na agitação (IVESON et al., 2001).

Neste trabalho foi estudado o método de produção de partículas aglomeradas de amido de milho por meio da atomização de solução de alginato de sódio e amido nativo em cloreto de cálcio. Adicionalmente, foram realizadas análises de microscopia eletrônica de varredura (MEV) e Potencial Zeta e espectroscopia de energia dispersiva (EDS), de forma a avaliar a ocorrência do recobrimento dos grânulos de amido nativo pelo alginato de cálcio.

\section{MÉTODOS}

\subsection{Potencial Zeta}

As análises do Potencial Zeta foram realizadas por medidas de mobilidade eletroforética, utilizando-se o equipamento Zeta Plus (Brookhaven Instruments Company, Holtsville, NY, EUA). As análises de dados se deu através do software incluído no sistema, o ZetaPlus. 
Para a realização das análises, a amostra foi diluída em soluções de cloreto de potássio, adicionado a solução de hidróxido de sódio em diferentes concentrações, para pHs, de 8 a 11, e adicionado a solução de ácido clorídrico para pHs de 3 a 6.

\subsection{Atomização da Solução de Alginato de Sódio e Amido de Milho em Cloreto de Cálcio}

Para a produção das partículas aglomeradas, utilizou-se $200 \mathrm{~mL}$ de solução aquosa de alginato de sódio a $1 \%$ (w/w). À solução de alginato de sódio, adicionou-se $20 \mathrm{~g}$ de amido de milho. A solução aquosa de cloreto de cálcio a $1 \%(\mathrm{w} / \mathrm{w})$ foi mantida em agitação utilizando-se um agitador magnético. A solução de alginato de sódio e amido de milho foi atomizada sobre a solução de cloreto de cálcio por meio de um bico aspersor (Figura 1), à vazão de 5,0 $\mathrm{mL} / \mathrm{min}$. Utilizou-se um bico aspersor tipo dois fluidos, mantendo-se a pressão do ar em 1 bar.

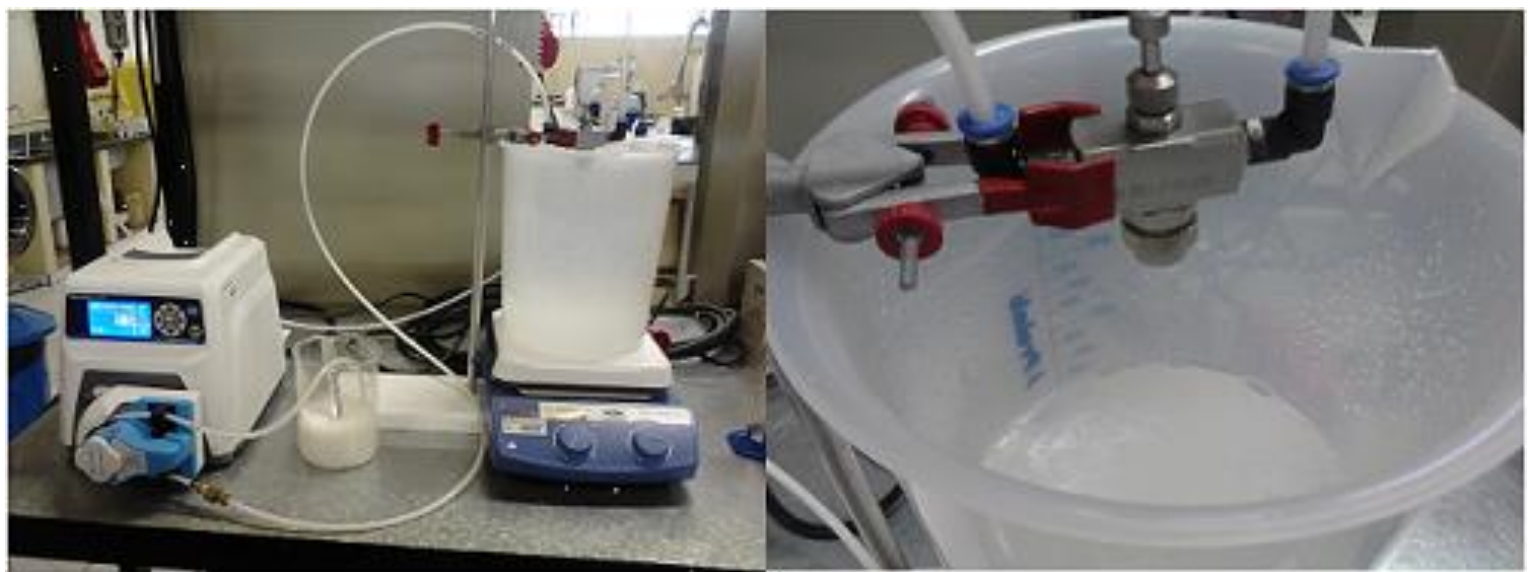

Figuras 1 - Atomização da solução de alginato de sódio e amido de milho em solução aquosa de cloreto de cálcio.

\subsection{Microscopia Eletrônica de Varredura}

As análises de microscopia eletrônica de varredura (MEV) e de espectroscopia de energia dispersiva (EDS) foram realizadas por meio do microscópio eletrônico HITACHI, Modelo TM3000, Japão.

\section{RESULTADOS E DISCUSSÃO}

\subsection{Potencial Zeta}

A Figura 2 mostra o gráfico do potencial zeta do amido de milho e do alginato de sódio em função do $\mathrm{pH}$. 


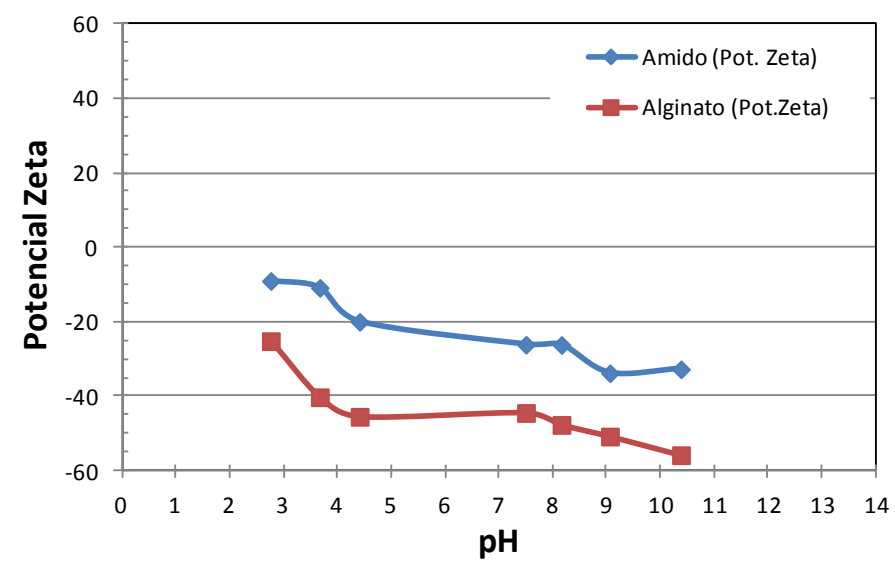

Figura 2 - Gráfico do Potencial Zeta versus pH.

Observou-se, através do gráfico obtido, que os potenciais Zeta do amido de milho e do alginato de sódio são negativos, ou seja, ambos possuem carga superficial negativa.

\subsection{Atomização de Alginato de Sódio e Amido de Milho em Cloreto de Cálcio}

As partículas produzidas pela atomização da suspensão de amido de milho e alginato de sódio sobre a solução de cloreto de cálcio apresentaram um aspecto gelificado. As partículas foram filtradas e submetidas à secagem convectiva em estufa a $65^{\circ} \mathrm{C}$ e também por liofilização, resultando em dois produtos diferentes, como pode ser observado na Figura 3. O produto seco por liofilização apresentou-se na forma de uma estrutura porosa, formada por pequenas partículas aglomeradas, enquanto as partículas secas por estufa formaram uma placa compacta e rígida, necessitando serem trituradas para a formação de um pó.

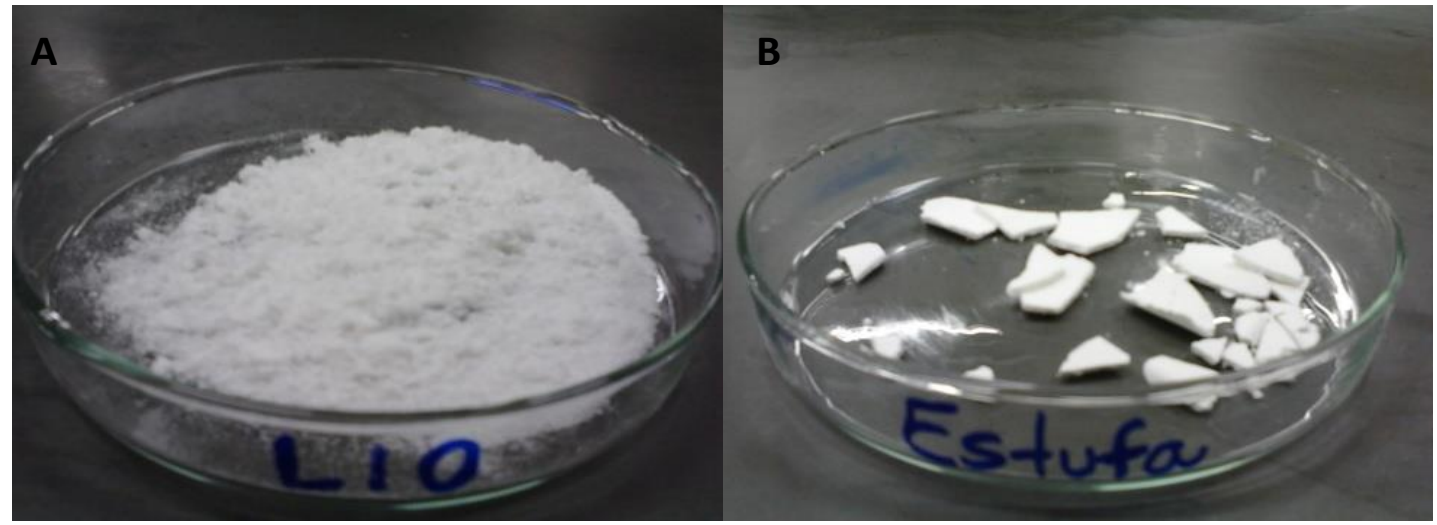

Figura 3 - A) Amido de Milho Liofilizado; B) Amido de Milho seco em estufa a $65^{\circ} \mathrm{C}$.

Os dois produtos foram analisados pelo microscópio eletrônico de varredura (MEV), gerando micrografias e análises de EDS.

As micrografias obtidas puderam ser observadas pela Figura 4. Observa-se que nas 
micrografias do amido de milho de milho "in natura", os grânulos de amido encontram-se separados, um a um, enquanto nas micrografias referentes aos secos em estufa e aos liofilizados, os grânulos apresentaram-se na forma de aglomerados, indicando que nos dois métodos de secagem ocorreu a agregação de partículas. Nas micrografias referentes às secagens em estufa e aos liofilizados, observou-se a formação de pontes sólidas, devido à adição do agente ligante.
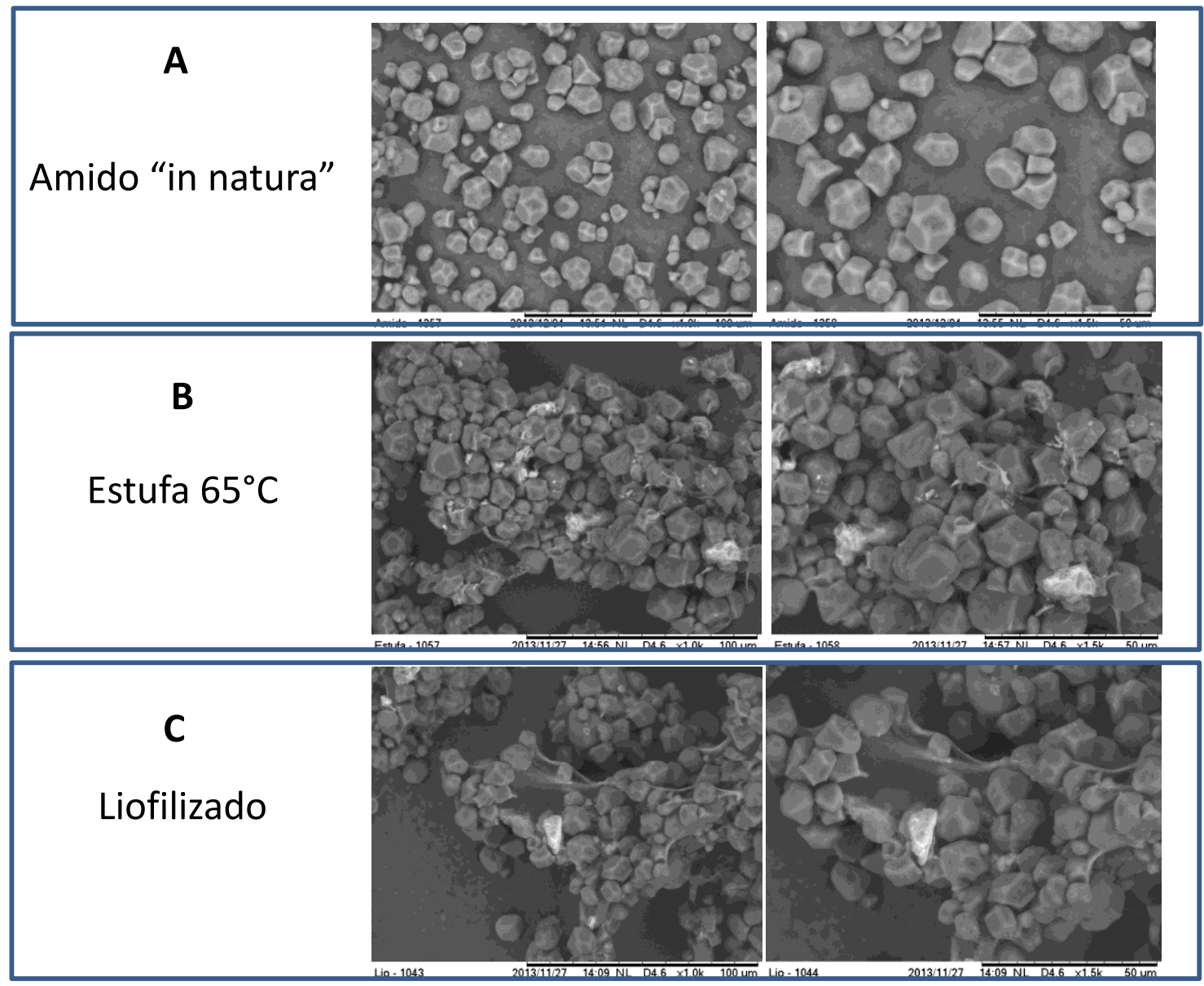

Figura 4 - Microscopia eletrônica de varredura de amido de milho (A) "in natura", (B) seco em estufa a $65^{\circ} \mathrm{C}$ e (C) liofilizado.

Pelas análises de EDS, foram obtidas as imagens que podem ser observadas na Figura 5 para amido de milho "in natura", na Figura 6, para amido de milho seco em estufa e na Figura 7 para amido de milho liofilizado. 

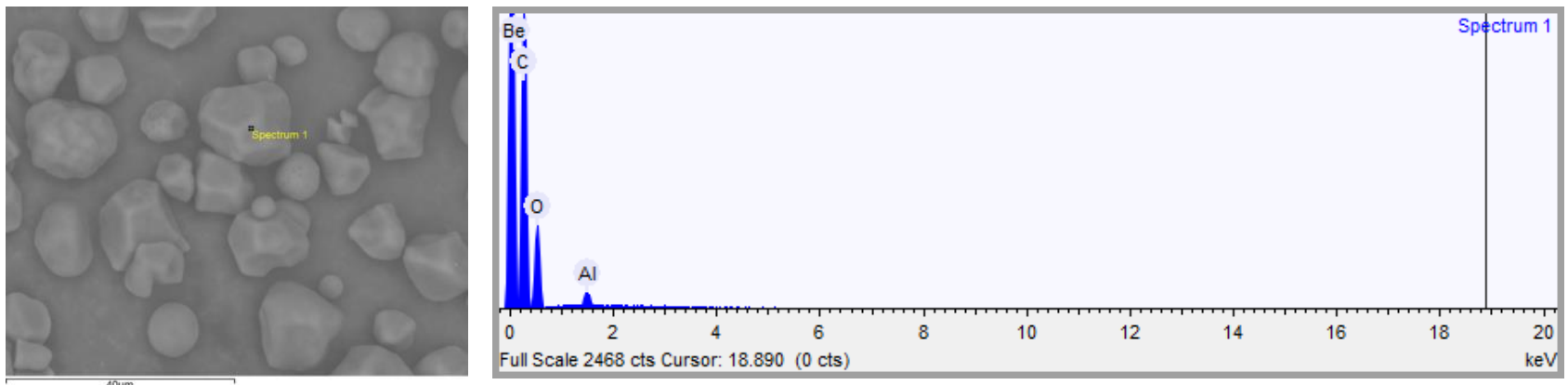

Figura 5 - Ponto tomado e gráfico gerado por análise de EDS para amido de milho in "natura"
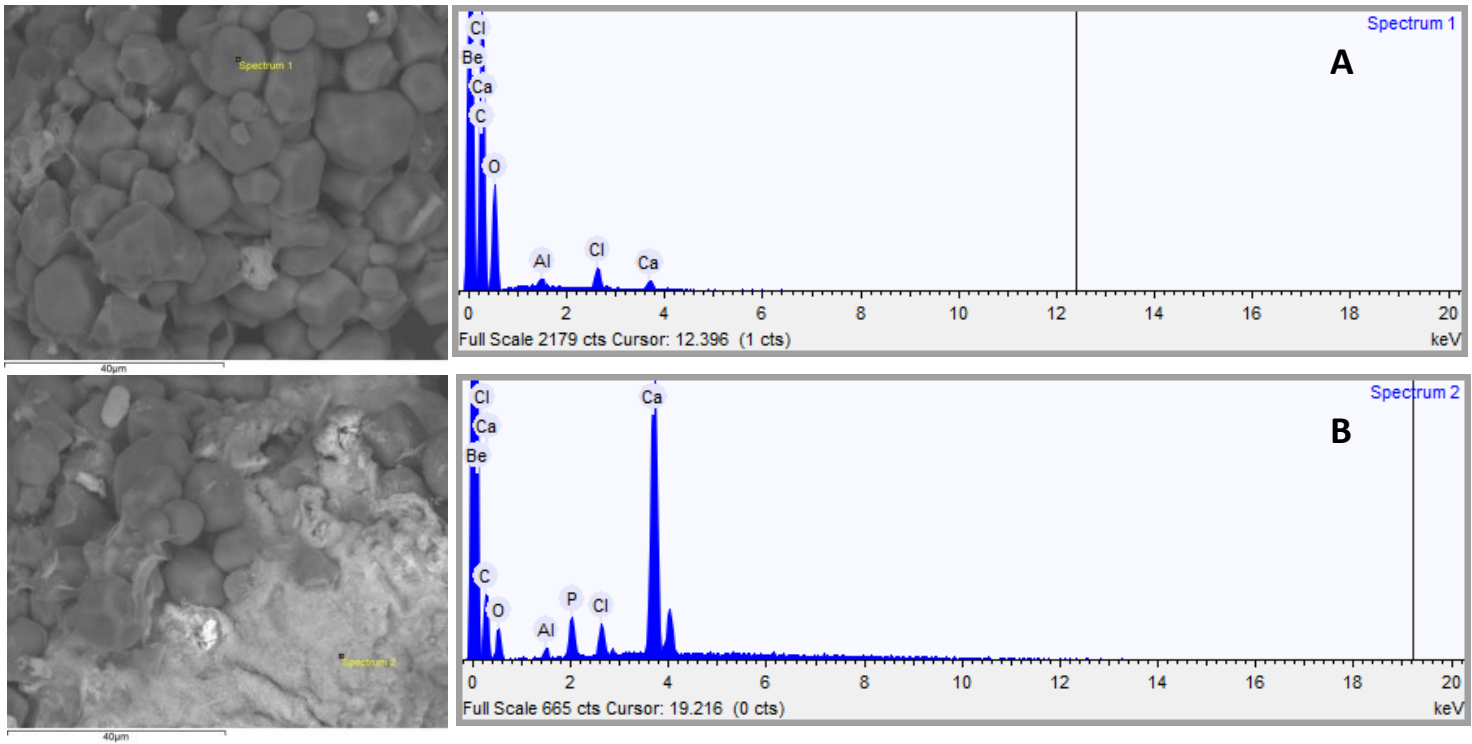

Figura 6 - Pontos tomados e gráficos gerados por análise de EDS para amido de milho seco em estufa (A) ponto sobre grânulo; (B) ponto sobre ponte sólida. 

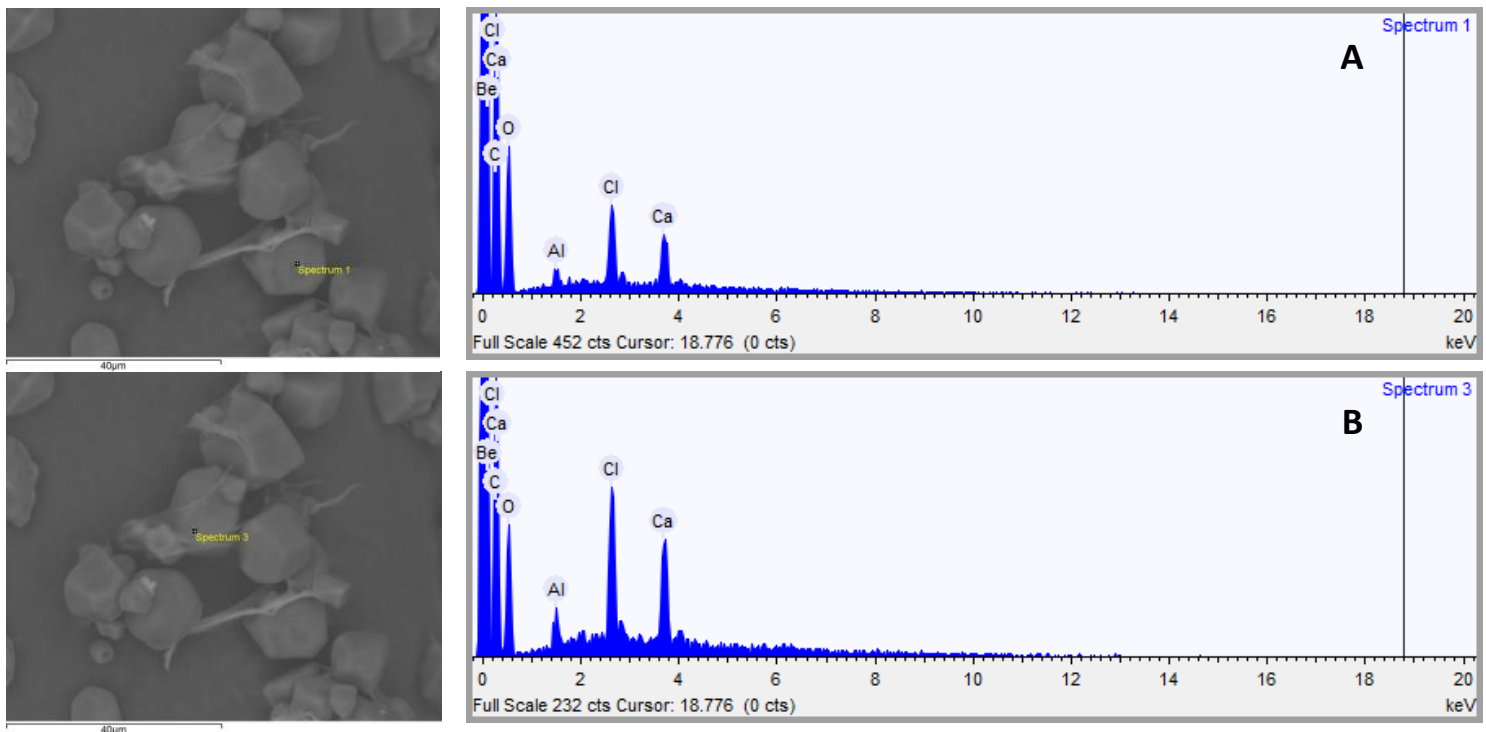

Figura 7 - Pontos tomados e gráficos gerados por análise de EDS para amido de milho seco em estufa (A) ponto sobre grânulo; (B) ponto sobre ponte sólida.

Através da comparação entre as Figuras 5 e 6, foi possível observar que em relação ao amido de milho "in natura", o amido de milho produzido seco em estufa apresentou picos dos elementos cloro e cálcio, presentes no ligante cloreto de cálcio, indicando sua presença no produto final. Na Figura 6, nos dois espectros gerados (A e B), observou-se que a intensidade dos picos dos elementos são diferentes entre eles. Isso acontece porque em A o ponto tomado para análise foi sobre um grânulo de amido, enquanto em B foi sobre uma ponte sólida de alginato de cálcio, onde a quantidade de tais componentes é maior.

O amido de milho produzido liofilizado analisado por EDS também apresentou picos de cloro e de cálcio que não foram observados no espectro do amido de milho "in natura", como pode ser observado na Figura 7. Os diferentes pontos tomados (A e B) deram origem a picos de cloro e cálcio de diferentes intensidades. O ponto A indica a análise de EDS sobre grânulo de amido de milho nativo, enquanto no ponto em $\mathrm{B}$ a análise foi realizada sobre uma ponte sólida de alginato de cálcio.

\section{CONCLUSÃO}

Diante dos resultados obtidos nas análises de micrografias, concluiu-se que o processo de aglomeração de partículas de amido de milho utilizando-se solução de alginato de sódio e subsequente atomização em solução de cloreto de cálcio foi satisfatório. Porém, observou-se através das análises de EDS e de potencial zeta, que não houve um recobrimento total dos grânulos de amido de milho pelo alginato de sódio. Este fenômeno é provavelmente justificado pela presença de uma mesma carga superficial negativa, determinadas pelas análises de potencial Zeta do amido de milho e alginato de sódio. 


\section{REFERÊNCIAS}

COPELAND, L.; BLAZEK, J.; SALMAN, H.; TANG, M. C. Form and functionality of starch. Food Hydrocolloids, v. 23, p. 1527-1534, 2009.

DACANAL, G.C. Aglomeração de polpa de acerola e proteína isolada de soja em pó em leito fluidizado cônico e pulsado. Tese (Doutorado), Faculdade de Engenharia de Alimentos, Universidade Estadual de Campinas (UNICAMP), Campinas, SP, Brasil, 2009.

DACANAL, G. C.; MENEGALli, F. C. Experimental study and optimization of the agglomeration of acerola powder in a conical fluid bed. Powder Technology, v. 188, p. 187194, 2009.

DONALD, A. M. Plasticization and self-assembly in the starch granule. Cereal Chemistry, v. 78, p. 307-314, 2001.

IVESON, S. M.; LITSTER, J. D.; HAPGOOD, K.; ENNIS, B. J. Nucleation, growth and breakage phenomena in agitated wet granulation processes: A review. Powder Technology, v. 117, p. 3-39, 2001.

MANNERS, D. J. Recent development in our understanding of amylopectin structure. Carbohydrate Polymers, v. 11, p. 87-112, 1988.

MUA, J. P.; JACKSON, D. S. Fine structure of corn amylose and amylopectin fractions with various molecular weights. Journal of Agricultural and Food Chemistry, v. 45, p. 38403847, 1997.

SINGH, J.; DARTOIS, A.; KAUR, L. Starch digestibility in food matrix: a review. Trends in Food Science \& Technology, v. 21, p. 168-180, 2010.

SINGH, J.; KAUR, L.; MCCARTHY, O. J. Factors influencing the physico-chemical, morphological, thermal and rheological properties of some chemically modified starches for food applications-a review. Food Hydrocolloids, v. 21, p. 1-22, 2007.

SINGH, N.; SINGH, J.; KAUR, L.; SODHI, N. S.; GILL B. S. Morphological, thermal and rheological properties of starches from different botanical sources. Food Chemistry, v. 81, p. 219-231, 2003.

TESTER, R. F.; KARKALAS, J.; QI, X. Starch - composition, fine structure and architecture. Journal of Cereal Science, v. 39, p. 151-165, 2004.

TURCHIUli, C.; ELOUALIA, Z.; EL-MANSOURE, N.; DUMOULIN, E. Fluidised bed agglomeration: Agglomerates shape and end-use properties. Powder Technology, v. 157, p. 168-175, 2005. 